\title{
Design and technological optimization of rubber-reinforced thin-layer movable joints in the structure of a pipeline vibration-isolating compensator
}

\author{
Galina Shaidurova $^{*, a}$ (iD), Oleg Milman $b$ (iD), Aleksey Kiryukhin ${ }^{b}$ iD, Aleksandr Shaidurov ${ }^{a}$ iD \\ ${ }^{a}$ Perm National Research Polytechnic University, Perm, Russia \\ ${ }^{b}$ Kaluga State Tsiolkovsky University, Kaluga, Russia
}

https://doi.org/10.54139/revinguc.v28i3.47

\begin{abstract}
Thin-layer rubber-metal elements have been widely used in various fields of technology, including helicopter construction, support parts for bridges, shock absorbers in industrial and civil construction. Their work reliability is determined by the design and technological performance features, which require experimental testing and parametric optimization. The article presents the samples and basic models testing results which were aimed at increasing the strength indicators stability of the adhesive "rubber-metal" joints and ensuring the failure-free operation of a rubber-metal product in the structure of a pipeline vibration-isolating compensator.
\end{abstract}

Keywords: elastomer; shear modulus of elasticity; polyisoprene; synthetic rubber; shear adhesion; adhesive polymer composition.

\section{Diseño y optimización tecnológica de juntas móviles de capa delgada reforzadas con caucho en la estructura de un compensador aislante de vibraciones de tubería}

Resumen.- Los elementos de caucho-metal de capa fina se han utilizado ampliamente en diversos campos de la tecnología, como la construcción de helicópteros, las piezas de soporte para puentes y los amortiguadores en la construcción industrial y civil. Su fiabilidad en el trabajo viene determinada por las características de diseño y rendimiento tecnológico, que requieren pruebas experimentales y optimización paramétrica. El artículo presenta las muestras y los resultados de las pruebas de los modelos básicos que tienen como objetivo aumentar la estabilidad de los indicadores de resistencia de las uniones adhesivas "caucho-metal" y garantizar el funcionamiento sin fallos de un producto caucho-metal en la estructura de un compensador aislante de vibraciones de tuberías.

Palabras clave: elastómero; módulo de elasticidad al cizallamiento; poliisopreno; caucho sintético; adhesión al cizallamiento; composicón polimérica adhesiva.

Received: October 23, 2021.

Accepted: November 29, 2021.

\section{Introduction}

Elastic movable joints that serve as damping elements are known due to their use in a variety of applications. Due to their specific properties (good adhesive strength, specific shear

\footnotetext{
* Correspondence author:

e-mail.shaidurova.g.i@mail.ru (G. Shaidurova)
}

deformation up to 100 - $300 \%$, high vibrationisolating and dissipative properties), low-modulus elastomers are increasingly used in various industries (aviation, rocketry, bridge structures, shipbuilding, seismic protection). One of the applications is the creation of thin-layer rubber-metal elements (TRME), which are elastic elements of vibration-isolating compensators for high-pressure pipelines [1]. Due to the TRME properties, compensators based on them have, in comparison with serial compensators (based on 
bellows, rubber-cord sleeves and shells) of the same diameter and pressure, better vibration- isolating properties in a wide frequency range [2, 3].

\subsection{Thin-layer Rubber-Metal Elements (TRME) design}

The design of a flat annular TRME is shown in Figure 1. It is a package of alternating flat annular layers of rigid reinforcing elements (spherical or conical versions are also possible) and layers of highly elastic rubbers based on natural or synthetic polyisoprene raw rubber with minimal intermolecular friction. Connection between the layers is carried out using various systems of adhesive polymer compositions, which, after covulcanization with a rubber layer, provide adhesive shear strength from 3 to $8,5 \mathrm{MPa}$, depending on the hardness of the elastomer vulcanizate. As a rule, an object as a product part (compensator) is operated with the compression and shear of the support rings axes, fixed with the moving and stationary pipeline parts or another structure, as shown in Figure 2 .

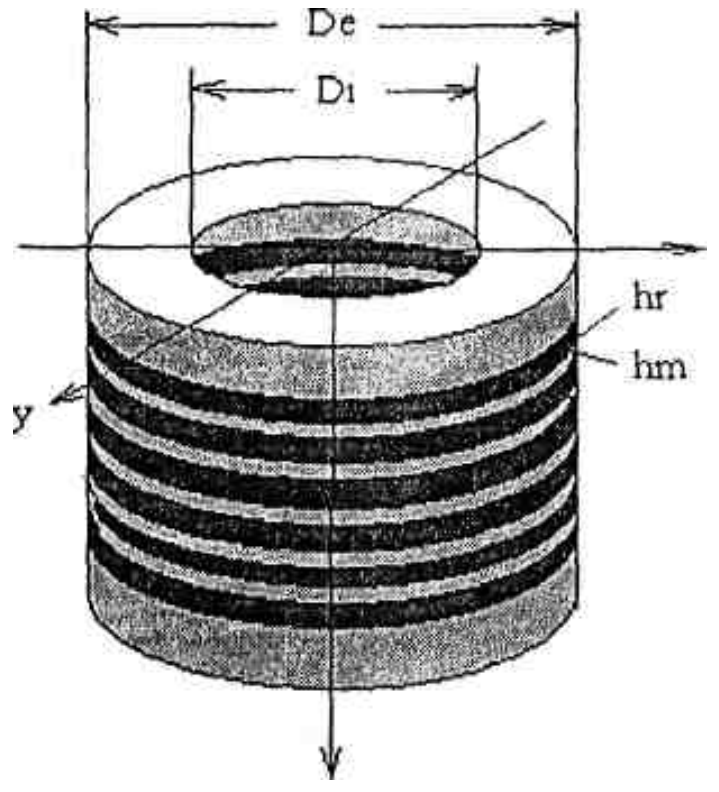

$D e, D i$ are the outer and inner diameters of the TRME support rings, $h r$ is the rubber layer thickness, $h m$ is the metal reinforcing plate thickness.

Figure 1: Design features of a flat annular TRME - an element of a compensator elastic flexible joint

Figure 2 shows the design diagram of the TRME deformation as a compensator part with the mutual displacement of the lower and upper support rings by the value e. The arrows show the effect of internal pressure $\mathrm{p}$ and axial compression force. Plane A moves relative to the lower rigidly fixed plane $B$ by the value e. During the TRME operation, additional loads occur in it due to temperature and cyclic deformations with a significant amplitude of up to $10 \mathrm{~mm}$, as well as vibration effects with relatively small amplitudes of up to $0,5 \mathrm{~mm}$, but valid for the entire service period (up to 30 years).

The design and calculation of the rigidity and vibration-isolating TRME properties and structures based on them have been considered in [4, 5]. In [6], the results of numerical modeling of the stress-strain state for a plane TRME with allowance for thermal deformations using the finite element method based on the variational approach have been considered.

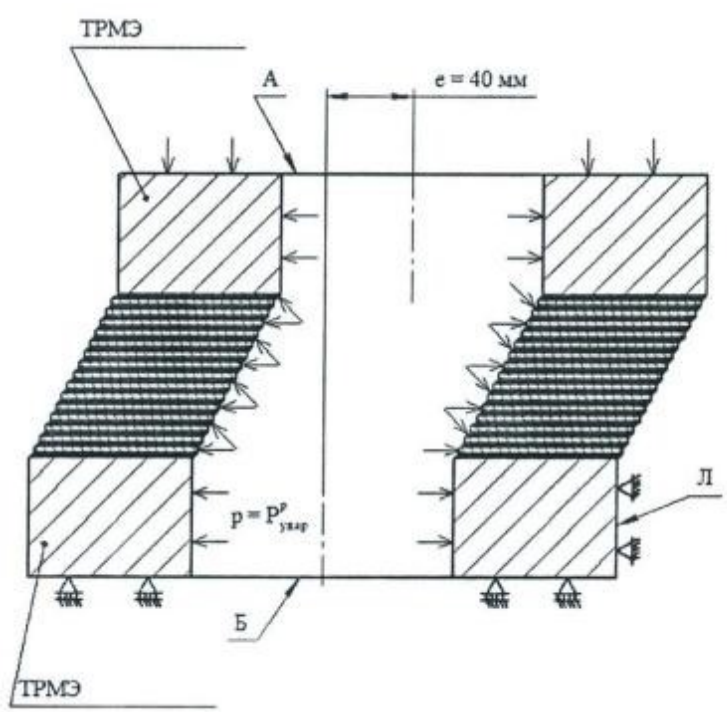

Figure 2: Design scheme of TRME deformation as a compensator part

\subsection{Elastomer selection}

The reliable functioning of the TRME as an expansion joint part primarily depends on the characteristics of the elastomers and adhesive compositions used to connect the elastomer layers to metal plates and flanges. This required a thorough and extensive design and technological development and optimization of the individual 

samples parameters and TRME as a whole. At the same time, the use of the Chemosil 211 adhesives system together with Chemosil 411 provided the required high level of adhesion strength at tear-off and shear.

\section{Methods}

The program for the TRME primary samples study included the following stages, as is shown in Table 1 .

- investigating the influence of the elastomer elasticity modulus magnitude at shear on the technical characteristics and reliability of the product;

- investigating the design effect (the ratio of the "metal-elastomer" thicknesses on the performance in the product composition);

- investigating the influence of metal surface preparation and the adhesive system on the elastomer adhesion strength in a multilayer structure.

The tests were carried out under the vibrations influence with amplitude from 0,5 to $10 \mathrm{~mm}$ and a variable frequency from 20 to $200 \mathrm{~Hz}$ with the results reproducibility with 5 representative samples for each option, Table 11. The most acceptable elastomer applications for this design were obtained for options 2 and 5 with a shear modulus of elasticity in the range of $0,24-0,28 \mathrm{MPa}$. In this case, cold-rolled carbon steel was used for the samples reinforcement. The thickness of the rigid reinforcing element should be close to the rubber layer calculated thickness, for example $1 \times 1$ or $1,5 \times 1,5 \mathrm{~mm}$.

The TRME failure criterion is tightness loss. The analysis of their nature has shown that the main reason for tightness loss is the violation of the adhesive rubber-metal connection (the layer separation) due to its insufficient adhesive strength. To create rubber-metal products with high performance characteristics, it is important to ensure not only the strength of the adhesive connection at the required level, but also its
Table 1: Options and test results for elastomer selection

\begin{tabular}{|c|c|c|}
\hline Elastomer & $\begin{array}{c}\text { Shear } \\
\text { modulus of } \\
\text { elasticity, MPa }\end{array}$ & Test results \\
\hline $\begin{array}{l}\text { 1.Polyisoprene with } \\
\text { fillers and a vulcanizing } \\
\text { group } \\
\text { Rubber thickness } \\
1,5 \mathrm{~mm} \\
\text { Metal thickness } 1 \mathrm{~mm}\end{array}$ & $0,18-0,22$ & depressurization \\
\hline $\begin{array}{l}\text { 2.Polyisoprene based } \\
\text { on SKI-3 } \\
\text { Rubber thickness } 1 \mathrm{~mm} \\
\text { Metal thickness } 1 \mathrm{~mm}\end{array}$ & $0,24-0,28$ & tightness \\
\hline $\begin{array}{l}3 \text { Polyisoprene accord- } \\
\text { ing to entry } 1 \\
\text { Rubber thickness } \\
1,5 \mathrm{~mm} \\
\text { Metal thickness } 1 \mathrm{~mm}\end{array}$ & $0,18-0,22$ & $\begin{array}{l}\text { Depressurization, } \\
\text { fragments } \\
\text { flying }\end{array}$ \\
\hline $\begin{array}{l}\text { 4. Polyisoprene accord- } \\
\text { ing to entry } 2 \\
\text { Rubber thickness } \\
1,5 \mathrm{~mm} \\
\text { Metal thickness } 1 \mathrm{~mm}\end{array}$ & $0,24-0,28$ & $\begin{array}{l}\text { Depressurization, } \\
\text { fragments } \\
\text { flying }\end{array}$ \\
\hline $\begin{array}{l}\text { 5. Polyisoprene accord- } \\
\text { ing to entry } 2 \\
\text { Rubber thickness } \\
1,5 \mathrm{~mm} \\
\text { Metal thickness } 1,5 \mathrm{~mm}\end{array}$ & $0,24-0,28$ & tightness \\
\hline
\end{tabular}

stability, namely, the indicators values constancy within the established limits of the so-called control limits. The solution to the problem of ensuring a high level and adhesive strength stability was secured by the materials optimal choice and strict adherence to the adhesive preparation procedures. Obtaining a high-quality rubber-metal connection depends, first of all, on the metal surface state, the rubber compound properties and adhesive, as well as the adopted manufacturing technology.

For rubber-metal products that require high rubber elasticity during the entire service period (the modulus value at a shear deformation of $100 \%$ is of the order of $0,25 \mathrm{MPa}$ ) in combination with high physical, mechanical and adhesive characteristics, a rubber compound based on SKI polyisoprene raw rubber was used in combination with a liquid-phase divinyl raw rubber with active end groups, acting as a plasticizer in the formulation. 


\section{Research development}

The laboratory tests results using samples and its testing in the products structure showed that the rubber compound based on this raw rubber provides an optimal complex of elastic and strength properties and most fully meets the above mentioned requirements. In addition to its high strength and adhesive ability, the SKI-3NT polyisoprene raw rubber has the best technological properties: while rolling it immediately forms a dense smooth workpiece and has an increased vulcanization rate. The physical and mechanical characteristics of rubber developed on the basis of polyisoprene raw rubber are shown in Table 2 .

Table 2: Physical and mechanical characteristics of a SKI-3NT based rubber compound

\begin{tabular}{l|c}
\hline \hline \multicolumn{1}{c|}{ Characteristics description } & $\begin{array}{c}\text { Characteristics } \\
\text { value }\end{array}$ \\
\hline Density, $\mathrm{kg} / \mathrm{m}^{3}$ & $1,05 \times 10^{3}$ \\
\hline Hardness, Shore units & $23-33$ \\
\hline Elongation at break, \%, not less & 700 \\
\hline $\begin{array}{l}\text { The rubber - metal connection strength } \\
\text { through the adhesive system at tearing off, }\end{array}$ & 2,5 \\
MPa, not less & \\
\hline $\begin{array}{l}\text { Conditional strength at rapture, MPa, not less } \\
\text { Shear modulus of elasticity at 100 \% } \\
\text { deformation, MPa }\end{array}$ & $0,18-0,22$ \\
\hline \hline
\end{tabular}

The above mentioned rubber compound has passed the stage of technological development with positive test results for the impact of all the necessary operational factors.

\subsection{Increasing adhesion strength}

Taking into account the experience of developing critical technology products, a system of adhesives, consisting of a primer and a cover adhesive, is used for high-quality metal - rubber connection. The primer adheres well to the metal and the top adhesive provides adhesion to the elastomer. The adhesives have effective mutual adhesion and contain different solvents to exclude the possibility of primer dissolution during the cover adhesive application [7, 8].

The next step is to provide a strong, reliable "rubber-metal" connection after selecting the rubber composition and a two-layer adhesive system is the surface preparation of the metal reinforcement.

Metal products can be cleaned either mechanically or chemically. The choice of the metal surface treatment method was carried out according to the adhesive strength value. The adhesive strength at rapture of the samples was determined in accordance with GOST 209-75 [9]. The test results are presented in Table 3 .

According to the research carried out, the greatest value of the adhesive strength at rapture is provided by sandblasting the metal. The use of chemical surface preparation for connecting led to a decrease in adhesion compared to sandblasting, apparently due to the smoothing of the surface relief. However, the highest level of adhesion is achieved with sandblasting followed by chemical oxide phosphating.

Table 3: Sample adhesion strength dependence on the surface preparation method

\begin{tabular}{l|c|c}
\hline \hline \multicolumn{1}{c|}{ Surface preparation method } & $\begin{array}{c}\text { Roughness } \\
\text { class, } \\
\text { microns }\end{array}$ & $\begin{array}{c}\text { Strength } \\
\text { at tearing- } \\
\text { off, MPa }\end{array}$ \\
\hline Sandblasting & 23,2 & 4,5 \\
\hline $\begin{array}{l}\text { Cadmium oxide phosphated } \\
\text { coating }\end{array}$ & 5,4 & 2,2 \\
\hline $\begin{array}{l}\text { Zinc coating with oxide phos- } \\
\text { phating }\end{array}$ & 6,8 & 1,2 \\
\hline $\begin{array}{l}\text { Chemical oxide phosphate coat- } \\
\text { ing }\end{array}$ & 12,2 & 3,2 \\
\hline Chemical phosphate coating & 9,2 & 2,2 \\
\hline $\begin{array}{l}\text { Sandblasting followed by oxide- } \\
\text { phosphate coating }\end{array}$ & 18,7 & 5,3 \\
\hline \hline
\end{tabular}

The experience of the assembled TRME testing showed that the use of the selected adhesive system ensures the endurance of repeatedly acting alternating loads by the adhesive connection. To ensure the operability of the multilayer rubbermetal structure, the performance indicators of the adhesive systems must not only exceed the values of the stresses acting in the adhesive connection, but also be stable, i.e. must be in a statistically stable state [10]. The adhesive system chosen for rubbermetal products until recently (until 2003) ensured a high and stable level of adhesion (Figure 5). The value of the rubber - metal adhesive strength at shear was not less than 3,17 $\mathrm{MPa}$ (with the required value of not less than $3,0 \mathrm{MPa}$ ), and at tearing off 
$7 \mathrm{MPa}$ (with the required value not less than 1,5 MPa). Stability was confirmed by the absence of parameter values outside the control limits determined by the equation (1).

$$
X=\bar{X}_{0}-1,6 \cdot \sigma_{0}
$$

where $\bar{X}_{0}$ is the average parameter value, $\sigma_{0}$ is the standard deviation.

To further increase the adhesive strength of the elastomer attachment to the metal, various technology options of applying the adhesive system were tested. The solution to this problem was carried out on rubber-metal samples manufactured with various options of applying adhesive systems. The assessment was carried out according to the level of the adhesive connections strength. The following technology options of adhesive application were chosen:

1- regular (primer + cover adhesive);

2- primer with a temperature-controlling operation introduced into the technology + cover adhesive;

3- primer + cover adhesive with vulcanizing additives introduced into its composition;

4- temperature-controlling primer + top adhesive with vulcanizing additives;

5- primer + temperature-controlling adhesive.

Comparative values of the rubber-metal adhesive strength using a system of adhesives with different technology options are shown in Figure 3 .

\section{Discussion of results}

From the presented diagram, it can be seen that in relation to the standard method of applying adhesives, the tested options made it possible to significantly increase the adhesive strength of the elastomer attachment to the metal at shear and tearing-off (option 2). The maximum value of the adhesive strength of the elastomer - metal connection at tearing-off was obtained with the introduction of an additional primer temperaturecontrolling operation.

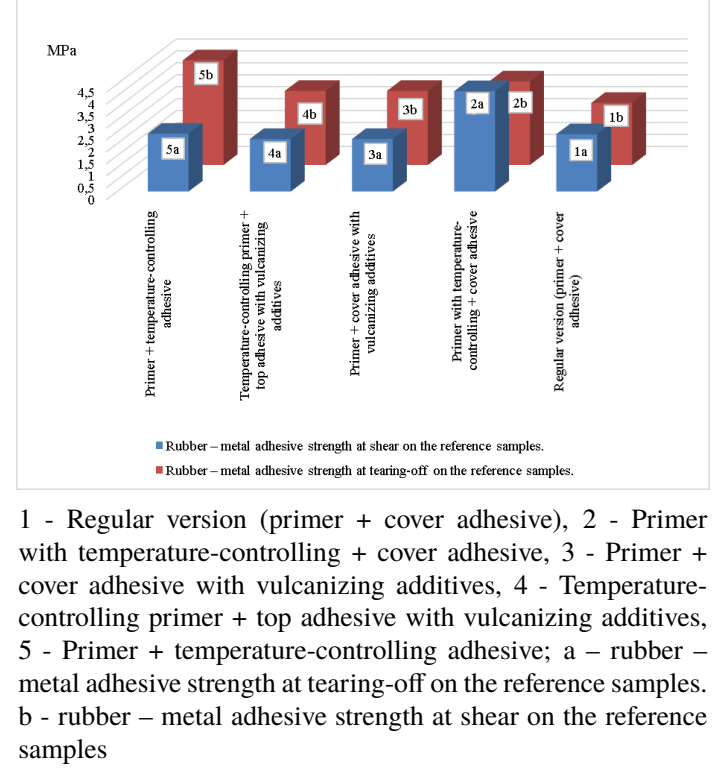

Figure 3: The adhesion characteristics level with variant adhesive systems options.

Significant differences in the adhesive bond strength value were obtained through the study of domestic and imported adhesive systems (Chemosil systems, Germany). The test results are shown in Figure 4

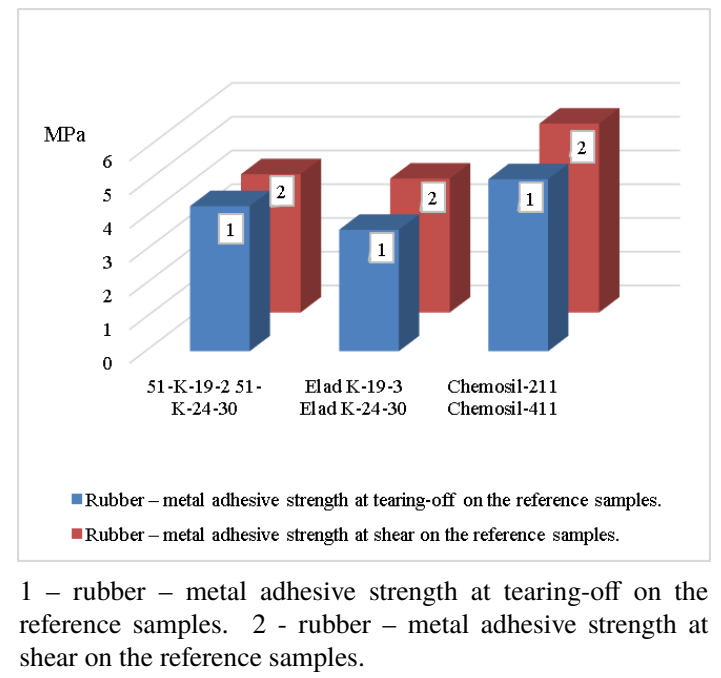

Figure 4: Comparative adhesion strength of the adhesive "metal - rubber" connection of domestic adhesives and adhesives "Chemosil" on the reference samples

The development of a domestic adhesives new system provided an increase in the adhesive 
compositions performance by almost 1,5 times, Figure 5 .

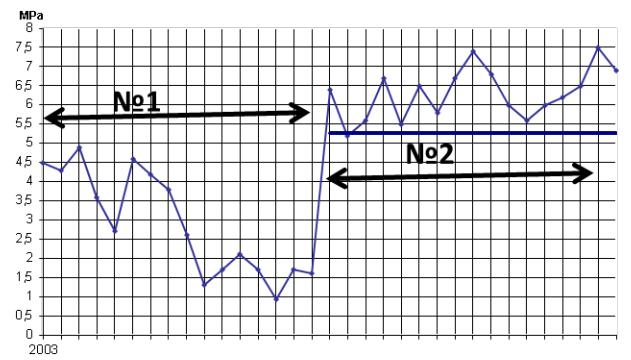

(a) rubber-metal connection strength at tearing off

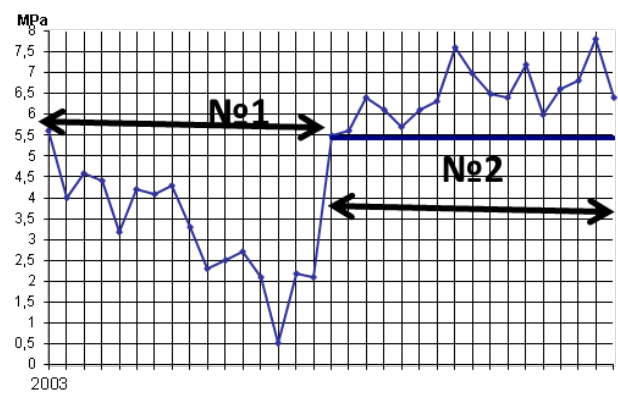

(b) rubber-metal connection strength at shear when using two adhesive systems options

Figure 5: Adhesion characteristics values. The first adhesives system №1, new adhesives system № 2

At the same time, the adhesive strength stability of the adhesive connection using the new adhesives system № 2 is confirmed by the results of the products manufacture to date, the parameters values are within the established regulation limits [10]. The analysis of the results obtained with the chosen option of adhesive systems with the same elastomer based on polyisoprene revealed the advantages of the newly developed formulations due to the chemical nature understanding of the components capable of forming adsorptionchemical connections [11, 12].

\section{Conclusions}

An analysis of the results obtained with a variant adhesive systems execution with the same elastomer based on polyisoprene revealed the advantages of the newly developed formulations, based on an understanding of the components chemical nature capable of forming adsorptionchemical connections.
The material science, technological and laboratory-experimental studies, their thorough analysis using mathematical statistics methods and the application of the results obtained in serial products, made possible the following:

1. to obtain the strength indicators stability of the rubber-metal adhesive connection with a significant excess of their initial level 2-2,5 times:

2. to ensure trouble-free rubber-metal product operation at high static, cyclic and vibration loads using a low-modulus hard-to-stick elastomer.

This allowed creating a new design of a thinlayer rubber-metal element that can significantly reduce vibration transfer along pipelines in power engineering, shipbuilding, and when pumping gas and oil.

\section{Acknowledgment}

This work was supported by the Russian Science Foundation. Project No. 21-1900311 of 20.04.2021 between the Russian Science Foundation and KSU named after K.E. Tsiolkovsky (Kaluga).

\section{References}

[1] A. Kirjukhin, O. Milman, A. Ptakhin, I. Serbin, and L. Serezhkin, "Experimental and Calculation Studies into the Possibilities of Improving the Vibration Isolation of Power Installation Pipelines," Thermal Engineering, vol. 67, no. 7, pp. 430-440, 2020. https: //doi.org/10.1134/S0040601520070046

[2] J. Dey, R. Mondal, and S. Halder, "Generalized phase compensator of continuous time plants." ISA Transactions, vol. 81, pp. 141-154, 2018. https://doi. org/10.1016/j.isatra.2018.07.043

[3] J. Van Schelt, D. Smith, N. Fong, D. Toomeh, P. Sponseller, D. Brown, M. Macomber, N. Mayr, S. Patel, A. Shulman, G. Subrahmanyam, K. Govindarajan, and E. Ford, "A ring-based compensator IMRT system optimized for low- and middle-income countries: Design and treatment planning study," Medical physics, vol. 45, no. 7, 2018. https://doi.org/10.1002/mp.12985

[4] A. Kiryukhin and S. Kravchenko, "Vibration-insulating Joints of High-pressure Pipelines Based on Thin-layer Rubber-metal Element," Vestnik Mashinostroeniya, vol. 10, 1989. 
[5] V. Tikhonov, "Design of Thin-layer Rubber-metal Elements for Vibration-isolating Supports and Forcemeasuring Transducers," Shipbuilding industry. Series: Marine power plants, no. 3, pp. 72-78, 1989.

[6] V. Modorsky, G. Shaidurova, R. Mormul', A. Kiryuhin, O. Mil'man, and A. Shaidurov, "Mathematical Simulations and Experiments on the Characterization of Stress-Strain State of Elastic Thin-layer Flexible Joints under Non-stationary Thermal Mechanical Loading ," International Journal of Emerging Trends in Engineering Research, vol. 8, no. 9, pp. 6553-6559, 2020. https://doi.org/10.30534/ijeter/2020/261892020

[7] M. Khorolsky, "Rubber-metal Products with New Properties for New Technologies and Objects Creation," in Theses of the scientific and technical conference reports. "Rubber and rubber", Moscow, 2010, pp. 353363.

[8] M. Sokolovsky, Advanced materials in rocket and space technology. Publishing house TORUS PRESS, 2007, ch. New Technologies in Rocket and Space Technology and Special Shipbuilding .

[9] USSR State Committee for Standards, GOST 20975Rubber and glue. Methods of determination of metal bond strength at tearing, USSR State Committee for Standards, 1975.

[10] D. Martin, Rubber Products Production and Use. Publishing house "Profession", 2013.

[11] S. Reznichenko and Y. Morozova, Big Reference Book of a Rubber Worker. Rubber and rubber products. Tekhinform Publishers, 2012, vol. 1.

[12] ASTM, D429-81 Standard Test Methods for Rubber property-Adhesion to rigid substrates., American Society for testing and materials, Philadelphia, 1993. 